\title{
Bacterial Cellulose-Chitosan-Glycerol Biocomposite as Artificial Dura Mater Candidates for Head Trauma
}

\author{
Rara Setya Angtika ${ }^{1}$, Prihartini Widiyanti ${ }^{1,2^{*}}$, Aminatun $^{3}$ \\ ${ }^{1}$ Biomedical Engineering Study Program, Faculty of Science and Technology, \\ Universitas Airlangga, Indonesia \\ ${ }^{2}$ Institute of Tropical Disease, Universitas Airlangga, Indonesia \\ ${ }^{3}$ Department of Physics, Faculty of Science and Technology, Universitas Airlangga, Indonesia \\ *Corresponding author: pwidiyanti@fst.unair.ac.id
}

Keywords: bacterial cellulose, chitosan, glycerol, biocomposite membrane, artificial dura mater

\begin{abstract}
Bacterial cellulose used for many membrane applications such as artificial dura mater membrane. This research aimed to determine the effects of glycerol concentration variation as plasticizer on physical and biological characteristics of bacterial cellulose-chitosan biocomposite membrane.Bacterial cellulose-glycerol membrane was soaked for six hours in $0.5 \%$ chitosan solution together with glycerol at various concentrations of $0.5 \%, 1 \%, 1.5 \%$, and $2 \%$. Based on results of FTIR test, there is a crosslinking between -OH groups in bacterial cellulose and chitosanglycerol. Meanwhile, results of the physical characteristic tests showed tensile strength value of 29.40 MPa for the control sample and 142.24 MPa for samples of bacterial cellulose-chitosan added $2 \%$ glycerol. It indicates that the addition of glycerol can increase tensile strength value. Results of morphological test, depicted pore size of 93.30-216 $\mathrm{nm}$. Results of the degradation test demonstrated that samples added $2 \%$ glycerol degraded as much as $50.15 \%$ for 2 weeks. Meanwhile, results of the cytotoxicity test indicated that all of samples were not toxic. Finally, it can be concluded that the best result of the characterization analysis was found on the samples added $2 \%$ glycerol although they have not yet fulfilled the standard value of artificial dura mater.
\end{abstract}

\section{Introduction}

Based on data from WHO, the prevalence of traffic accidents with head injuries in many developing countries, such as Indonesia was high, as much as 90\%. Traffic accidents with head injuries are considered to be severe problems since they can lead to death or other negative impacts. Based on data recorded in Police of the Republic of Indonesia in 2011, the number of accidents reached 108,696 with 31,195 deaths and 35,285 sustained serious injuries. It is also known that $55.1 \%$ of the accident victims suffered from severe concussions or broken blood vessels in their brain.

Head injuries, such as concussions, tumors, and blood vessel breakdowns, attacking dura mater can interfere with the supply of cells, including oxygen and nutrients, especially glucose. Dura mater is the outermost and most substantial meningeal layer of the central nervous system (CNS) that acts as a protective membrane of the brain and spinal cord [1].

As a result, in dealing with the case, a skull surgery is required. However, the skull surgery will not always go as expected. For instance, cranial operation with a small incision or cutting on the dura mater is capable of causing a leakage of spinal fluid [2]. After the skull surgery, the skull of patients is often infected and makes their brain fluid spilling out. This cerebrospinal fluid leakage is also known as cerebrospinal leakage (CSF leakage). Cerebrospinal fluid leakage is the loss of fluid and pressure from the spinal fluid due to a hole in the dura mater. The dura mater is usually covered with stitches, which means a small hole in the dura mater covered with a surgical sealant film [3].Consequently, to prevent the brain fluid from spilling out, an artificial dura meter is required to replace the membrane.

Artificial dura meter in a previous research was made from bacterial cellulose by using Acetobacter xylinum bacteria fermented in certain media. The bacterial cellulose considered as a 
biodegradable natural polymer has a high mechanical strength [4] as much as $17 \mathrm{MPa}$, potential to meet the characteristics of an ideal dura meter, namely biocompatible or capable of repairing the dura mater defect in rabbits and no CSF Cerebrrospinal Fluid) leakage, abscess, as well as inflammatory response [5]. In addition to having superior properties, the bacterial cellulose also has a weakness that is easily contaminated by microbes. Consequently, a modification is required to obtain chemical, morphological, and molecular structures as well as to enhance desirable bioactive properties used as a cover for deficiencies in bacterial cellulose. Such modification may be accomplished by adding active polysaccharides, such as chitosan. Chitosan itself has a fairly wide usage in medical. Chitosan fibers are used as sewing threads in surgery that can be absorbed by the human body, as a bandage covering the wound, and as a drug carrier. Chitosan also affects the blood clotting process, so it can be used as haemostatics. Cellulose and chitosan have similar molecular structures, with the same b-glycoside linkages. The main difference is the presence of primary amino groups at the C-2 positions in chitosan, where cellulose has hydroxyl groups. The presence of active groups in chitosan's molecular structure allows for easy chemical modifiation. Cellulose and chitosan are both biocompatible, nontoxic, and have been used extensively for biomedical applications.

Based on a previous research conducted by Ciechanska [7], bacterial cellulose-chitosan biocomposite material has been tested in vitro by analyzing antibacterial activity. This previous research shows that the biocomposite has bacteriostatic activity against Gram (-) and (+) bacteria as well as bacterial activity against Gram $(+)$ bacteria. Another previous research conducted by Widiyanti $\mathrm{P}$ et al [8]. shows that the mechanical results of tensile test indicate a tensile strength value of $8.58 \mathrm{MPa}$ close to the artificial magnetic tensile strength $(7.05 \mathrm{MPa})$ found in a research conducted by Damien et al [9]. However, the material produced is still too rigid and less flexible. As a result, plasticizer is required to add to improve its properties. The addition of plasticizer aims to increase the fleaxibility and weaken the polymer stiffness by using glycerol as its plasticizer.

Therefore, this research aimed to determine the right formula to get a composite membrane for dura mater applications that have characteristics as expected by using the superior properties of both polymers in which the bacterial cellulose-chitosan biocomposite membrane as an artificial duramater candidate with a concentration of $0.5 \%$ presents, by optimizing the variation of glycerol composition with concentrations of $0.5 \%, 1 \%, 1.5 \%$, and $2 \%$, as well as by using the freeze-dried technique.

Next, there were several characterization tests performed in this research, namely Tensile test to reveal mechanical strength, Fourier Transform Infra Red (FTIR) test to detect functional groups in membrane, morphology test using Scanning Electron Microscope (SEM) to determine the pore size of a sample, as well as degradation test using Simulated Body Fluid (SBF) solution and cytotoxicity test using MTT Assay to obtain quantitative data derived from poliferation results in order to measure the number of living cells [10].

\section{Research Methods}

\section{Materials}

Materials used in this research were bacterial cellulose, starter derived from Acetobacterxylinum bacteria, coconut water, sugar, acetic acid, chitosan, alcohol, and aquadest. A test instrument used for analyzing functional group was FTIR Shimadzu 8400S, while an instrument used to reveal the morphological structure of membrane was Scanning Electron Microscope (SEM) (Inspect S50, Fei Corp, Japan). Moreover, an instrument used for tensile test was Imada HV-500NII, Japan in order to reveal the tensile strength of membrane. Meanwhile, an instrument used for Cytotoxicity test was microwell plate and ELISA Reader (Thermo Scientific Multiscan EX) using MTT Assay method. 


\section{Methods}

Bacterial Cellulose Synthesis

$1000 \mathrm{ml}$ of filtered coconut water +100 grams of sugar $+20 \mathrm{ml}$ acetic acid + glycerol at various concentration $(0.5 \%$, $1 \%, 1.5 \%$, and $2 \%$ ) were stirring until dissolved

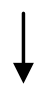

The mixture was acidified by added $\mathrm{CH}_{3} \mathrm{COOH}$ until the $\mathrm{pH} 4$ while boiling. After the mixture was boiled, it was poured in sterilized fermented closed container and put it in autoclave in order to remain sterilized and uncontaminated.

Bacterial

Cellulose

Synthesis

Chitosan solution was prepared by dissolving $2 \mathrm{ml}$ of acetic acid into $100 \mathrm{ml}$ of distilled water for 20 minutes then added chitosan $0.5 \%$ to make membrane using bacterial cellulose. 
Bacterial Cellulose-Chitosan-Glycerol Biocomposite Synthesis
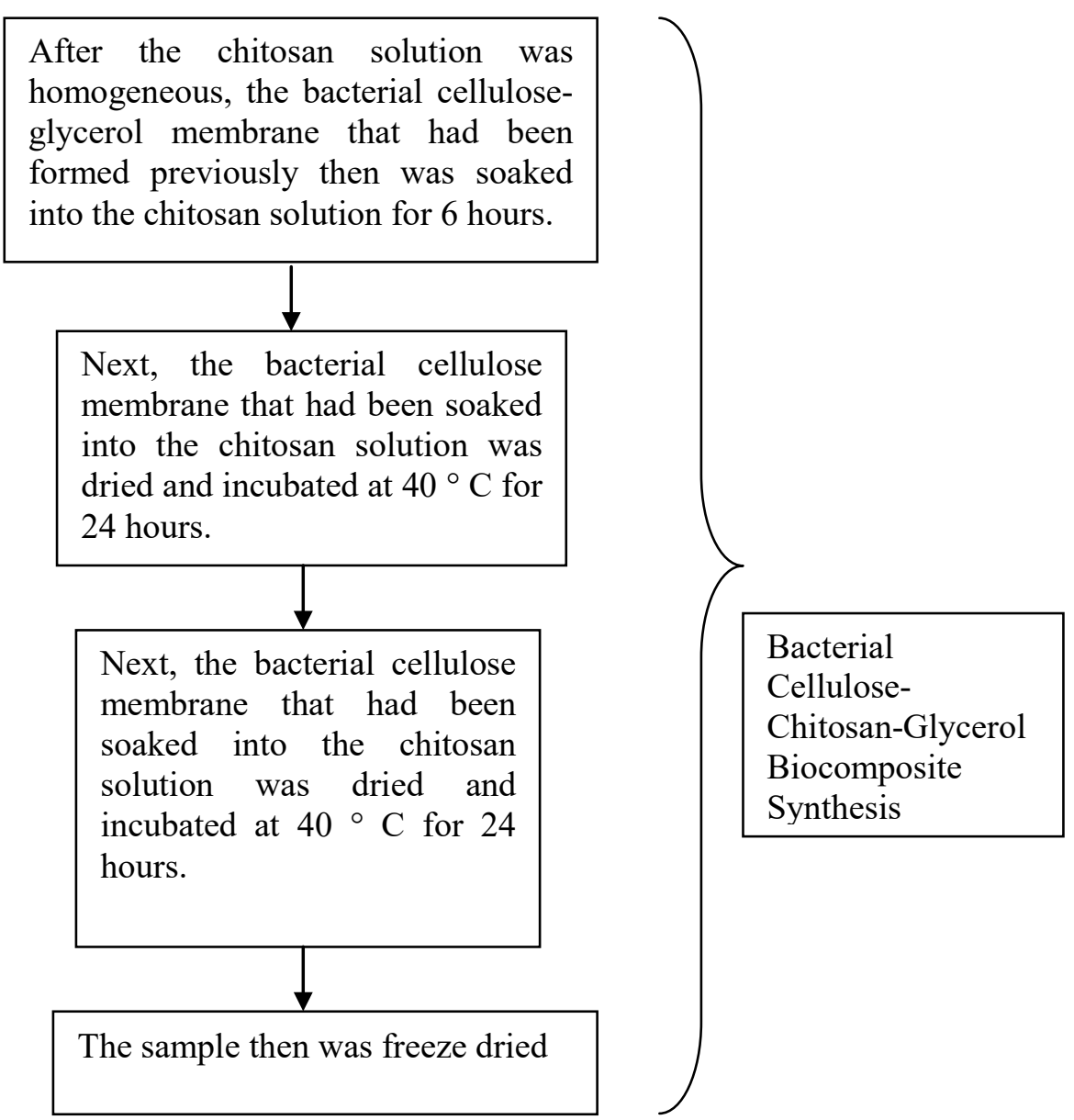

Functional Group Test using Fourier Transform Infrared Spectroscopy (FTIR)

Characterization of the functional groups of composite compounds was analyzed using Shimadzu 8400S Fourier Transform Infrared Spectrometry (FTIR). Next, samples were prepared with clay-like shapes. Afterwards, the samples were placed on the infrared ray of the FTIR for approximately 1 minute. The characterization then was performed by analyzing the peaks formed on the IR spectrum.

\section{Tensile Strength Test}

For tensile strength test,an instrument used was standardized Imada HV-500NII, Japan. Next, the thickness of the membranesin the sampleswas measured using Coating Thickness Gauge TT 210 type. They then were cut into pieces in the form of dumb bell sized 50x5 mm. The maximum load imposed on the sampleswas $50 \mathrm{~N}$. After the sampleswere pulled and stretched until reaching its maximum tensile strength, the changes in length (11) were measured. The maximum tensile strength (Fmax) and graph of each sample would be displayed on computer screen.

\section{Degradation Test}

Degradation test was performed to find out how long the samples could survive in the body when applied. Test method used was in vivo or in vitro performed using Simulated Body Fluid (SBF) solution media [11]. The membrane was immersed in a sterile SBF solution at $37^{\circ} \mathrm{C}$ for 3 to 12 weeks. The percentage of the weight of the degraded membrane then was analyzed by the length of immersion time. 
Morphological Test using Scanning Electron Microscope (SEM)

Morphological test was performed using Scanning Electron Microscopy (SEM) (Inspect S50, FEI Corp, Japan) to examine surface structure, pore diameter, porous layer, non-porous layer, and membrane thickness [12]. Next, the samples were cut in millimeters (mm), and coated with goldpalladium $(80 \% \mathrm{Au}$ and $20 \% \mathrm{Pd})$. The morphological structure of the samples then was illustrated on photos of the sample surface.

Cytotoxicity Test

BHK-21 cell culture in monolayer form with Eagle's media was incubated for 48 hours, and then washed with PBS. Next, it was inserted in $100 \mu \mathrm{L}$ of medial (86\% Eagle's media, $1 \%$ Penicillin streptomycin, 100 units / $\mathrm{mL}$ of Fungizone), and then transferred to 96-microwell plates. Afterwards, DMSO solvent was added to every well as much as $50 \mu \mathrm{L}$, and then centrifuged at $30 \mathrm{rpm}$ for 5 minutes. After the centrifugation process, optical density of the cells was calculated using Elisa Reader.

\section{Results and Discussions}

The samples of this research were derived from a bacterial fermentation process of Acetobacter xylinum, generating cellulose layers. Next, the bacterial cellulose layers formed were soaked in chitosan, and then freeze dry method was conducted. Afterwards, pellicle formation process was triggered by glucose isomeration process as a result of the metabolism of Acetobacter xylinum. Biocomposite synthesis process can be seen in Figure 1.

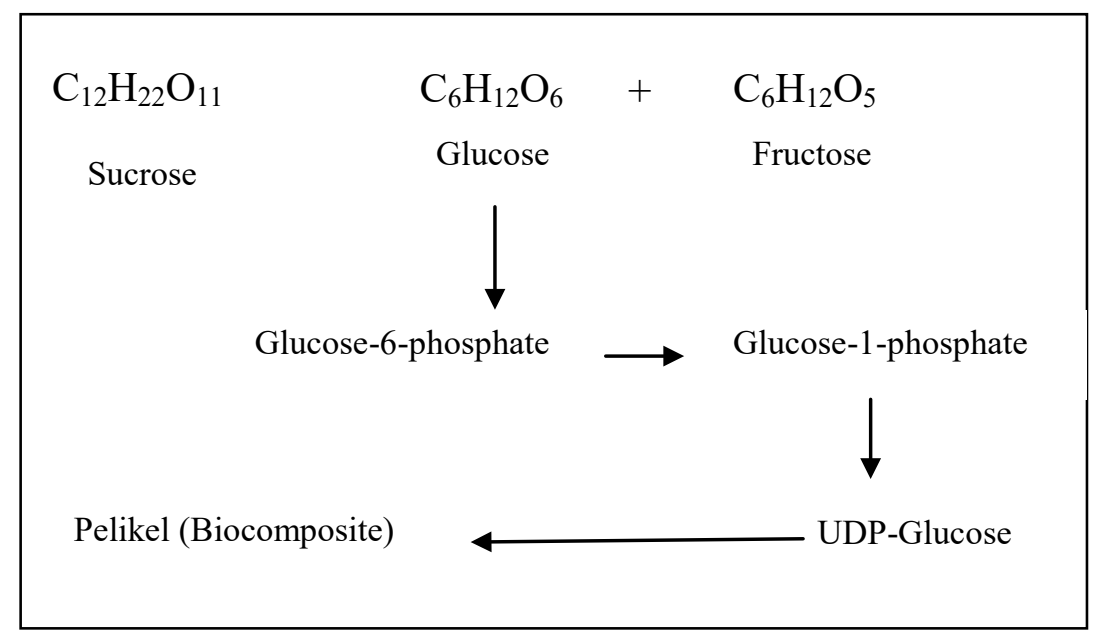

Figure 1. Synthesis Process of Bacterial Cellulose-Chitosan Biocomposite 
Functional Group Test Result using Fourier Transform Infrared Spectroscopy (FTIR)

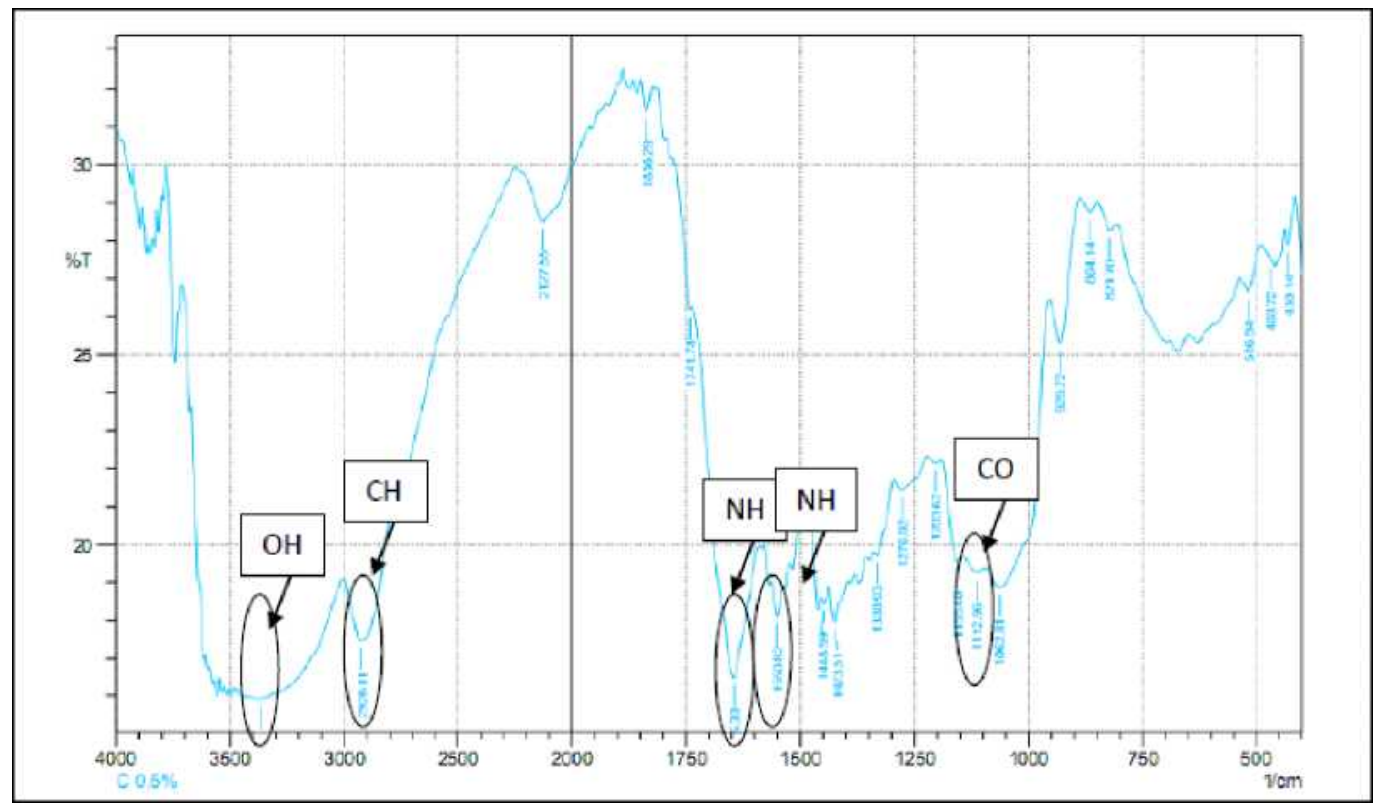

Figure 2. FTIR Spectra of Biocomposite Bacterial Cellulose - Chitosan 0,5\% Membrane

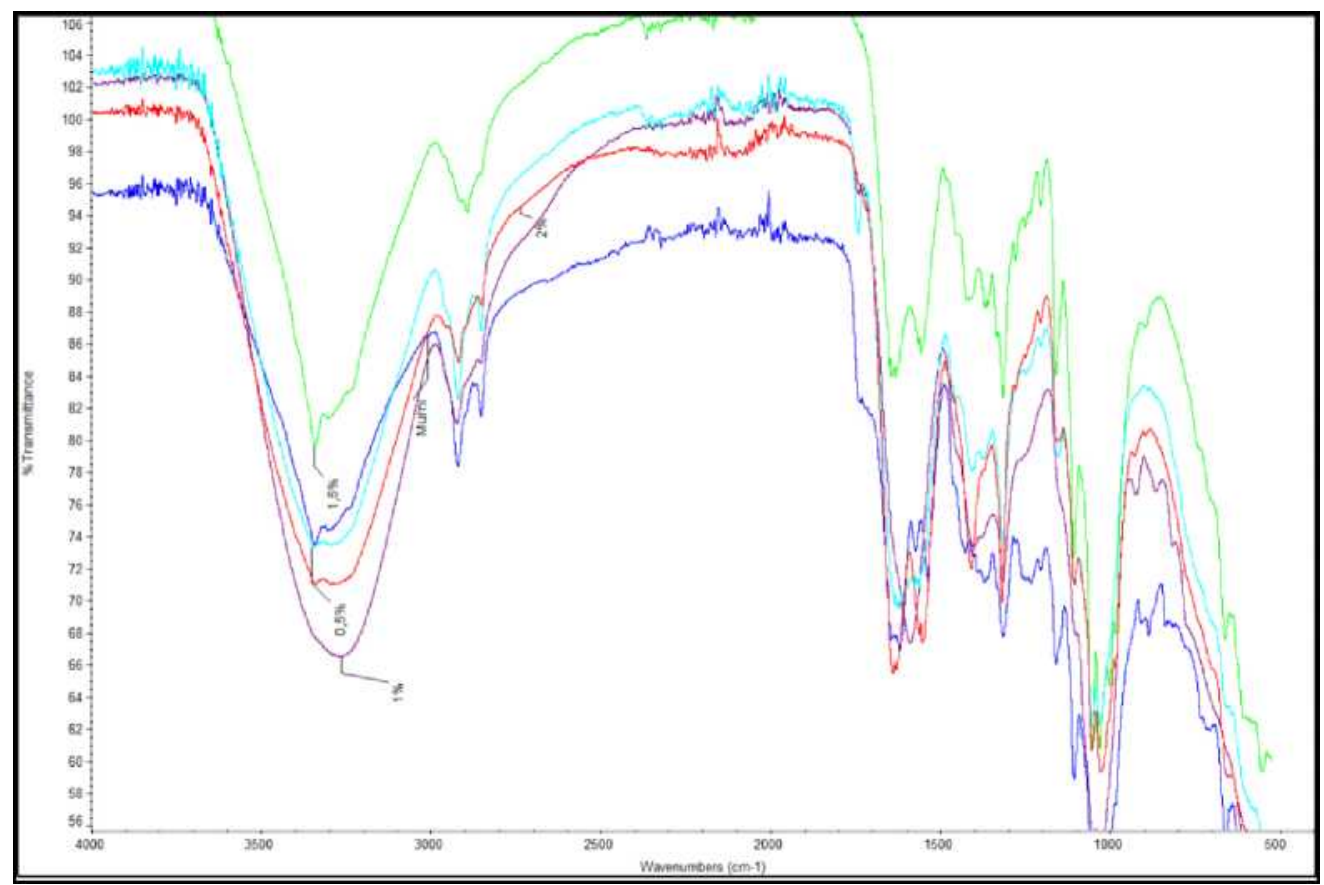

Figure 3. FTIR Spectra of Biocomposite Bacterial Cellulose - Chitosan with Variation Glycerol $0,5 \%, 1 \%, 1,5 \%$ dan $2 \%$

Analysis of the FTIR test results obtained from various variations of glycerol composition was conducted to reveal the interaction between bacterial cellulose-chitosan biocomposite and glycerol. The functional groups or bond types in the control samples and the samples of bacterial cellulosechitosan added glycerol containing - $\mathrm{OH}$ groups reached wide and strong peaks at positions of $3348.33,3272.50,3343.44$, and $3293 \mathrm{~cm}^{-1}$. Hydrogen bonds in the samples of bacterial cellulosechitosan added glycerol were derived from interactions between the bacterial cellulose molecules themselves as well as between the cellulose molecules with glycerol. The hydrogen bonds can be considered as a tensile strength among the hydrogen atoms in a polar bond, one of which is O-H. Thus, there will be a very strong tensile strength, hydrogen bond. The hydrogen bond will be stronger with Van der Waals bond. The more hydrogen bonds are, the stronger the structures 
formed by the molecules. Besides, the single $\mathrm{C}-\mathrm{O}$ bond in the samples was indicated by several wavelengths, namely $1054.74,1150.40,1055.59$, and $1054.75 \mathrm{~cm}^{-1}$. Meanwhile, the absorption of aromatic ring occured at a wavelength of 1015-1650 $\mathrm{cm}^{-1}$. Crosslinking of cellulose due to its hydrophobic-hydrophilic equilibrium, which gives rise to a collapse or an expansion of molecular chains by small temperature changes around its critical value [13].

Table 1. The Tensile Strength and Elongation Value of the Bacterial Cellulose-Chitosan- Glycerol Biocomposite

\begin{tabular}{|l|c|c|c|c|c|}
\hline $\begin{array}{c}\text { Sample } \\
\text { (Concentration } \\
\text { of Glycerol) }\end{array}$ & $\begin{array}{c}\text { Thickness } \\
(\boldsymbol{\mu m})\end{array}$ & $\begin{array}{c}\text { Fmax } \\
(\mathbf{N})\end{array}$ & $\begin{array}{c}\mathbf{A} \\
\mathbf{( m m}^{\mathbf{2}} \mathbf{)}\end{array}$ & $\begin{array}{c}\text { Tensile } \\
\text { Strength } \\
(\mathbf{M P a})\end{array}$ & $\begin{array}{c}\text { Elongation/ } \\
\text { Stain }(\mathbf{\%})\end{array}$ \\
\hline Control & 19.31 & 2.84 & 0.088 & 29.40 & 1.97 \\
\hline $0.5 \%$ & 17.6 & 2.83 & 0.076 & 32.15 & 2.17 \\
\hline $1 \%$ & 15.26 & 5.93 & 0.081 & 77.68 & 2.21 \\
\hline $1.5 \%$ & 16.35 & 9.91 & 0.116 & 121.28 & 2.24 \\
\hline $2 \%$ & 23.28 & 16.56 & 0.096 & 142.24 & 2.99 \\
\hline
\end{tabular}

The addition of glycerol can increase tensile strength and elongation value. The percentage of elongation value obtained in the control samples was $1.97 \%$, while the percentage of elongation value in the samples with glycerol $0.5 \%$ was $2.17 \%$. In addition, the percentage of elongation value in the samples with glycerol $1 \%$ was $2.21 \%$, and $2.24 \%$ in the samples with glycerol $1.5 \%$. And, the maximum increase in the percentage of elongation value was found in the samples with $2 \%$ glycerol, about $2.99 \%$ as could be seen in Table 1 . The increased elongation value in the samples of bacterial cellulose-chitosan-glycerol can occur since the glycerol molecule as plasticizer has a strong interaction force with the polymer, thus diffusing into the polymer chain. In this case, the plasticizer molecule will be located between the bacterial cellulose and chitosan polymer chains and also will affect the chains, leading to an increase in flexibility [14].

\section{Degradation Test Result}

The degradation test result of the samples could be seen in Table 2.

Table 2. Results of the Degradation Test on the Bacterial Cellulose-Chitosan-Glycerol Biocomposite

\begin{tabular}{|c|c|c|c|c|c|}
\hline \multirow{2}{*}{ Samples } & \multirow{2}{*}{$\begin{array}{c}\text { Initial } \\
\text { Mass }\end{array}$} & \multicolumn{2}{|c|}{ Sample Mass (g) } & \multicolumn{2}{c|}{ Degradation (\%) } \\
\cline { 3 - 6 } & & Day-7 & Day-14 & Day-7 & Day-14 \\
\hline Control & 0.0096 & 0.0072 & 0.0048 & 27.2714 & 49.7657 \\
\hline $0.5 \%$ & 0.0118 & 0.0089 & 0.0065 & 24.0528 & 45.7643 \\
\hline $1 \%$ & 0.0198 & 0.0157 & 0.0101 & 21.3944 & 48.4575 \\
\hline $1.5 \%$ & 0.0187 & 0.0154 & 0.0103 & 20.3810 & 41.9786 \\
\hline $2 \%$ & 0.0142 & 0.0106 & 0.0069 & 24.7744 & 50.1556 \\
\hline
\end{tabular}

As a result, it can be said that the addition of $2 \%$ glycerol can accelerate degradation. Due to the addition of glycerol, interconnected pore were formed faster in the samples of biocomposite membrane. Consequently, the hydrolytic properties in unstable chitosan were improved, then leading to the acceleration and control of the membrane degradation in the water medium. As a result, within 2 weeks the percentage of the degradation reached $50.15 \%$ suitable with the mass of fibroblast cell growth. This may occur due to the porous structure. Chitosan with higher DD has a less porous structure and lower water-uptake ability which limits the rate of the degradation process [15]. Chitosan with high DD was also shown to be more susceptible to degradation [16]. 


\section{Morphological Test Result using Scanning Electron Microscope (SEM)}

Based on results of the morphological test, the samples of the bacterial cellulose-chitosan-glycerol biocomposite had fibrous structure with a pore size of 93.30-216 nm. The image of SEM result could be seen in Figure 4.

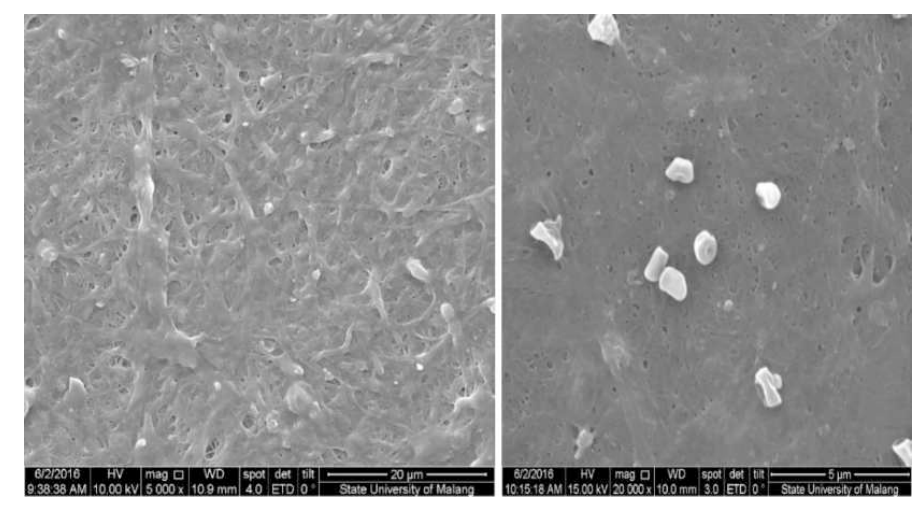

Figure 4. The Morphological Structure of the Bacterial Cellulose-Chitosan-Glycerol Biocomposite Membrane

The presence of the nano pore size in these artificial membranes can help cell infiltration and cell migration [16]. Thus, they will be more able to diffuse through the cavities between fibers as the result of the metabolism of Acetobacterxylinum and chitosan. The pore size of an artificial nanoduramater size must be within the range of 200-300 $\mathrm{nm}$ which enables the occurrence of cell attachment and fluid leakage prevention [5].

Cytotoxicity Test Result

The cytotoxicity result of the samples could be seen in Figure 5.

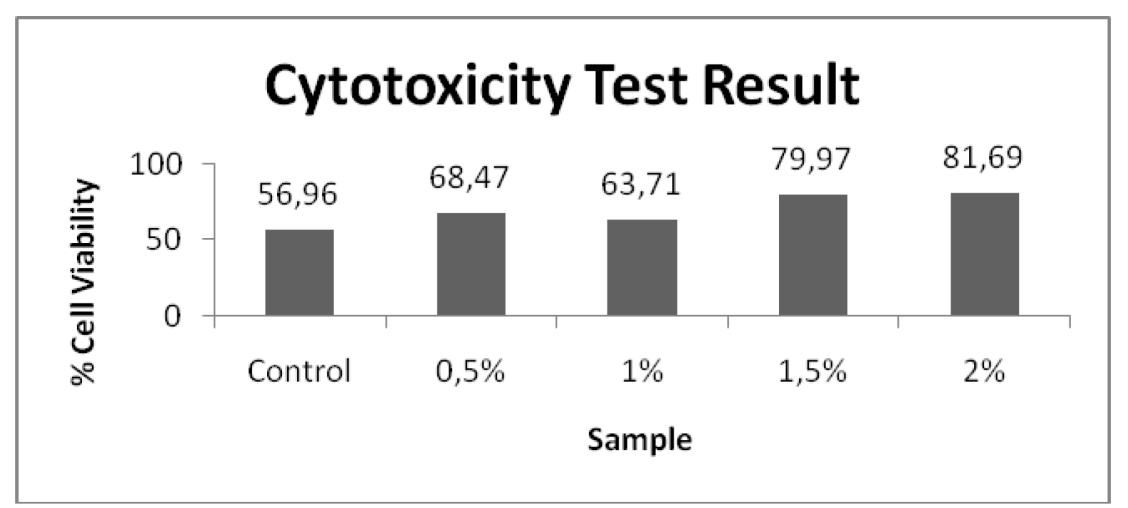

Figure 5. Graph of the Cytotoxicity Test Result on the Bacterial Cellulose-Chitosan- Glycerol Biocomposite

The difference in results of the MTT Assay test may be influenced by several factors, such as cell media missmatching with the samples, $\mathrm{pH}$, incubation temperature, organic solvent composition, and color difference in the samples. Based on the test results, the percentage of cell viability in all samples was $>50 \%$. Therefore, it can be said that all the samples of bacterial cellulose-chitosanglycerol as artificial dura mater candidates in this research were not toxic with the percentage of living cells above $50 \%$ [17]. The best composition was found in the samples with $2 \%$ glycerol due to the presence of $\mathrm{OH}$ group. The elongation percentage also increased as much as $2.99 \%$ in the samples with $2 \%$ glycerol. In addition, results of the morphological test showed the presence of fine fibers. Results of the degradation test also indicated degradation as much as $50.15 \%$. Finally, results of the cytotoxicity test revealed that the percentage of the cell viability was equal to $81.69 \%$, and they were not toxic. 


\section{Conclusion}

Bacterial Cellulose-Chitosan-Glycerol Biocomposite is showed the characteristic required for artificial duramater candidates due to the mechanical property and the cytotoxicity status. The degradation status is still need to be improved concerning of the attention to the healing concept and foreign body reaction.Eventhough it still need further research to optimized the characteristic which support the clinical usage.

\section{Acknowledgements}

The author would like to thank to the Material Physic Laboratory, Microbiology Laboratory, Faculty of Science and Technology Universitas Airlangga, Sepuluh November Technology Institute and Material and Metallurgy Faculty and Central Laboratory Universitas Negeri Malang, Material Physic Laboratory, Faculty of Mathematics and Natural Sciences Universitas Brawijaya Malang, Center Instalation of Biomaterial- Tissue Bank RSU dr.Soetomo Surabaya, and Pusat Veterinaria Farma (PUSVETMA) Surabaya for support in characterization.

\section{References}

[1] Weed, L.H, Meninges and Cerebrospinal Fluid. Journal Anatomi. 72 (1938) 181-215

[2] Ginsberg, Leonle, Lecture Note Neurology 8th Edition. USA : Blacwell Publishing, 2005

[3] Cosgrove, G. Reef, JB, Delashaw , JA, Grotenhuis , JM, Tew ., H, Van Loveren, RF, Spetzler, T, Payner ., G, Rosseau., ME, Shaffrey ., LN,Hopkins., R, Byrne ., A, Norbash, Safety and Efficacy of a Novel Polyethylene Glycol Hydrogel Sealant for Watertight Dural Repair. Boston: Massachussets General Hospital, 2007

[4] Lina et al, Bacterial Cellulose for Skin Repair Materials. Biomedical Engineering. China (2012) 249-269

[5] Xu Chen, Ma Xia, Chen Shiwen, Tao Meifeng, Yuan Lutao, and Jing Yao, Bacterial Cellulose Membranes Used as Artificial Substitutes for Dural Defection in Rabbits. International Journal for Molecular Science. China. 15 (2014) 10855-10867

[6] Jiufang Duan, Chunrui Han, Liujun Liu, Jianxin Jiang, Jianzhang Li, Yiqiang Li, and Chao Guan, Binding Cellulose and Chitosan via Intermolecular Inclusion Interaction: Synthesis and Characterisation of Gel Journal of Spectroscopy Volume (2015) Article ID 179258, p 1-6 http://dx.doi.org/10.1155/2015/179258

[7] Ciechanska, Danuta, Multifunctional Bacterial Cellulose/Chitosan Composite Material for Medical Applications. Journal of Fibers\& Textiles in Eastern Europe. Vol. 12. No. 4 (2004) 48

[8] Prihartini Widiyanti, Hajria Jabbar, Djony Izak Rudyardjo, Effects of variation of chitosan concentration on the characteristics of membrane cellulose bacteria-chitosan biocomposites as candidates for artificial dura mater. AIP Conference Proceedings 1817 (2017), 020011, doi: $10.1063 / 1.4976763$

[9] Damien, Jamer Cristopher et al, Dura Substitute and a Process for Producing the Same Provisional Application, 2008

[10]P. Roguet, R. Jones, P, The ECVAM International Validation Study on In VitroTests for Acute Skin Irritation: Report on the Validity of the EPISKIN and Epi Derm Assays and on the Skin Integrity Function Test. Germany: ATLA, 2007

[11] Vukelic M., Mitic, Z et al.,Interaction of biomaterials containing calcium hydroxyapatite/poly-1 lactide with the simulated body fluid, Acta medica medianae., 50 (4) (2011), 35-39 
[12] Sanchez S H, Zuniga R R, Anda de L S, Dellamary L F, Castaneda G R, Jaimes R C, Espinoza J G, A New Bilayer Chitosan Scaffolding as a Dural Substitute : Experimental Evaluation. World Neurosurg (2012) 77, 3/4: 577-582. DOI: 10.1016/j.wneu.2011.07.007

[13]Takigami, M.; Amada, H.; Nagasawa, N.; Yagi, T.; Kasahara, T.; Takigami, S.; Tamada, M. Preparation and properties of CMC gel. Trans. Mater. Res. Soc. Jpn., 32 (2007), 713-716

[14]Rahayu T, Rohaeti E, Sifat Mekanik Selulosa Bakteri dari Air Kelapa dengan Penambahan Kitosan. Universitas Negeri Yogyakarta. Yogyakarta, 2012

[15] Wanjun, T.; Cunxin, W.; Donghua, C, Kinetic studies on the pyrolysis of chitin and chitosan. Polym. Degrad. Stab.87 (2005) 389-394

[16]Bajer, D.; Kaczmarek, H. Study of the influence on UV radiation on biodegradable blends based on chitosan and starch, Progr. Chem. Appl. Chitin Deriv. 15 (2010) 17-24

[17] Spielmann, H. Hoffmann, S. Botham, P. Roguet, R. Jones, P, The ECVAM International Validation Study on In VitroTests for Acute Skin Irritation: Report on the Validity of the EPISKIN and EpiDerm Assays and on the Skin Integrity Function Test. Germany: ATLA, 2007 